\title{
Editorial
}

\section{Setting standards: from passing fashion to essential clinical activity}

Setting standards is a fashionable exercise. Under one heading or another it is keeping many people very busy. At the top the Department of Health is taking a lead by setting targets. Some targets, such as those for immunisation, form part of the payment system for general practitioners, others, most notably those embodied in the Health of the Nation ${ }^{1}$ are intended to set priorities for the whole health service for the next few years. Within the department are various committees to deal with audit, such as the Clinical Standards Advisory Group, which includes leaders and representatives of the medical, nursing, midwifery, and dental professions with an independent lay chairman, advising the secretary of state. ${ }^{2}$ Then there is the example of the King's Fund consensus conferences which have regularly set standards based on evidence provided to a multidisciplinary conference working to a tight deadline. In Europe, the Dutch College of General Practitioners has a rigorous procedure for standard setting, which entails several rounds of consultation with many specialists and general practitioners. ${ }^{3}$ Lastly, all clinicians are required to set or use standards as part of their contractual obligation to undertake clinical audit.

An impartial observer may view such activity with some cynicism. Is setting standards merely a passing fashion, where the show of intellectual rigour conceals endless recycling of previous conclusions or will it produce statements of real value? An unequivocal answer is difficult at this stage, but even now there is enough experience to give a few indicators.

Although setting standards is only the first step towards analysing and changing clinical behaviour, the process may in itself produce benefits. Much has been made of the value of audit as an educational tool, ${ }^{4}$ and some of the learning will be in the standard setting phase. For instance, one group reported this as the main benefit of having a practice prescribing formulary. ${ }^{5}$ However, some caution is called for. In this issue Newton et al, reporting an exercise of standard setting in small groups (p 256), ${ }^{6}$ emphasise that effective learning occurs only when the group is functioning well. Convening a local group to work on standards may provide an opportunity to bring together health professionals from different disciplines, with the potential to formulate comprehensive policies - for example, those crossing boundaries between primary and secondary care or between medicine and other professional groups. A successful example of this is the setting up of a formulary for primary and secondary care in the Grampian region. ${ }^{7}$ Another example is reported in this issue by Armstrong et al (p 241), ${ }^{8}$ in which standards in a district were drawn up for a set of obstetric problems by a process involving consultant obstetricians and general practitioners and revised after consideration of the views of all general practitioners in the district. The study illustrates both the strengths and weaknesses of this approach: getting consultants and general practitioners to work together at least means that one group need not feel that "experts" are imposing standards, but Armstrong et al candidly admit that the process may lead to a conclusion that owes more to the need to reach agreement than to the dictates of scientific rigour. This should not be an insuperable problem. If there is to be equality and cooperation between different disciplines each must be prepared to admit its own ignorance and to rethink its most cherished practices. An interdisciplinary group may be helped by being informed by literature supplied from an impartial source.

When it comes to influencing clinical behaviour the picture is more blurred. Some national bodies have issued guidelines for clinical practice that justify not carrying out certain procedures, which clinicians may find useful in influencing their own and their patients' expectations. For instance, the American College of Obstetricians and Gynecologists has advised that it is safe to monitor labour without electronic fetal monitoring, ${ }^{9}$ and the Royal College of Radiologists has stated that skull $x$ ray examinations are "not recommended routinely" for head injuries. ${ }^{10}$

More often standards imply exhortation to do more and not less. Standards set by national bodies working away from everyday clinical activity need to fulfil two criteria to be helpful. Firstly, it must be clear what individual clinicians have to do to achieve the standard. The widespread attainment of the national targets for immunisation shows what can be achieved when this occurs and is backed by a clear statement and other incentives. Other targets included in The Health of the Nation will be more difficult to attain. We should be able to reduce the incidence of cerebrovascular disease, where we know that some interventions, if successfully applied, could contribute towards achieving the target; what clinicians or anyone else can do to reduce the number of unwanted pregnancies in teenagers is much less clear. Secondly, the standards have to be attainable. It is easy for clinicians when not confronted by the reality of their own practice to lay down a standard which in theory looks reasonable but in practice may be as inaccessible as the holy grail. Standards such as those for the management of asthma drawn up by the British Thoracic Society are a statement of perfection. ${ }^{11}$ They can be useful in providing a starting point for discussion and in ensuring a rigorous reference point that embodies a consensus of the best possible achievable standards of care, but using them as they stand to measure their own performance may result in inducing a sense of failure among clinicians and precisely the opposite effect to that intended. Clinicians attempting to improve their own practice by using standards set by others must do so with caution. It is vital to observe the distinction between standards as the outcome to be achieved and criteria as the level of attainment for that standard.

All the reported work that has shown real improvements in clinical practice emphasises how important it is for those doing the work to own the standard. For example, in one study a group of doctors from different practices drew up a standard for prescribing digoxin. They took the agreed standard back to their practices and won apparent agreement from their partners, but it was only those who had been 
involved throughout whose behaviour changed. ${ }^{12}$ Similar results were reported from the large numbers of doctors from the Northern region involved in audit of paediatric care. ${ }^{13}$ In contrast, Marsh and Channing, working to improve health care to the deprived part of a practice, showed what astonishing improvements can be made when both the problem and its solution are seen by those in the practice team as their own property. ${ }^{14}$

Those who assess clinicians' performance, such as purchasing authorities for hospital doctors and medical audit advisory groups for general practitioners, need to accept that local standards are the only way to improve care, however far removed they are from the grandiose statement of more august bodies. That is one example of the subsidiarity principle with which we can all agree.

DAVID JEWELL

Consultant Senior Lecturer in General Practice,

Department of Epidemiology and Public Health Medicine,

University of Bristol,

Bristol BS8 1 TH

1 Department of Health. The health of the nation: a strategy for health in England. London: HMSO, 1992.

2 Higginson G. Role of the Clinical Standards Advisory Group. Quality in Health Care 1992;1(suppl):34-5.
3 Grol R. National standard setting for quality of care in general practice: attitude of general practitioners and response to a set of standards. $B r$ f Gen Pract 1990;40:361-4.

4 Coles C. Self assessment and medical audit: an educational approach. BMF 1989;299:807-8.

5 Field J. How do doctors and patients react to the introduction of a prescribing formulary? Fam Pract 1989;6:135-40

6 Newton J, Hutchinson A, Steen N, Russell I, Haimes E. Educationa potential of medical audit: observations from a study of small groups setting standards. Quality in Health Care 1992;1:256-9.

7 Garvey G, Jappy B, Stewart D, Williams A, Duffus PRS, Maitland JM et al. Grampian Health Board's joint drug formulary. $B M^{\mathscr{f}}$ 1990;301:851-2

8 Armstrong D, Tatford P, Fry J, Armstrong P. Development of clinical guidelines in a health district: an attempt to find consensus. Quality in Health Care 1992;1:241-4.

9 American College of Obstetricians and Gynecologists. Standards for obstetric-gynecology services 1989. 7th ed. Washington, DC: ACOG, $1989,35-7$.

10 Royal College of Radiologists Working Party. Making the best use of a department of radiology: guidelines for doctors. London: Royal College of Radiologists, 1989.

11 British Thoracic Society, Research Unit of the Royal College of Physicians of London, King's Fund Centre, National Asthma Campaign. Guidelines for management of asthma in adults. I. Chronic persistent asthma. BMF 1990;301:651-3.

12 Anderson CM, Chambers S, Clamp M, McGhee MF, Summer KR, Wood AM. Can audit improve patient care? Effects of studying use of digoxin in general practice. $B M \mathcal{A f} 1988 ; 297: 113-4$.

13 North of England Study of Standards and Performance in General Practice. Medical audit in general practice. I. Effects on doctors' clinical behaviour for common childhood conditions. BMF 1992;304:1480-4.

14 Marsh GN, Channing DM. Narrowing the health gap between a deprived and an endowed community. BMY 1988;296:173-6. 